\title{
SYNTHESIS OF SULFONAMIDE DEHYDROABIETANE DERIVATIVES OF AMINO ACIDS
}

\author{
D. Petukhov', S. Pestova² and E. Izmest'ev ${ }^{1,2}$ \\ ${ }^{1}$ Vyatka State University, 610000,Russia, Kirov, Moskovskaya, 36. \\ ${ }^{2}$ Institute of Chemistry, FRC Komi Scientific Centre, Ural Branch of the RAS, \\ 167982, Russia, Syktyvkar, Pervomaiskaya, 48.
}

DOI: 10.19163/MedChemRussia2021-2021-452

E-mail: usr20941@vyatsu.ru

Dehydroabietane-derived compounds possess a wide spectrum of biological activity, among which antiviral, antibacterial, antileishmania, antituberculosis, antitumor and antioxidant properties have been studied. They can be used to treat cardiovascular disease, gastric ulcer and SARS [1].

A promising area for further search for potential biologically activedehydroabietane type substances is the synthesis of their conjugates with amino acids. We have obtained a series of new compounds with fragments of methyl esters 3-13, 25 and hydrazides 14-24 of natural amino acids. In the case of lysine, bis-sulfonamide 26 and $\alpha$-naphthylacetic acid amidoanhydride 27 were also synthesized.

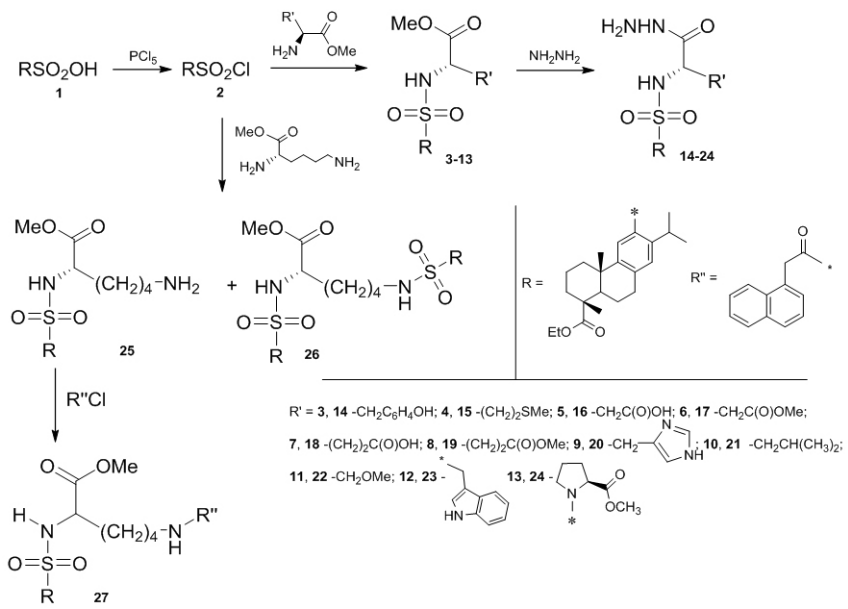

The reported study was funded by RFBR, project number 19-316-90019, with using the equipment of Chemistry Joint Center (Institute of Chemistry, Komi ScienceCenter, Ural Branch, Russian Academy of Sciences).

\section{References}

[1] A. Helfenstein, M. Vahermo, and D. A. Nawrot,Bioorganic \& Medicinal Chemistry.2017, V. 25, p. 132-137. 